\title{
Analysis of the Optimal Sharing of Construction Risk in Public Procurement Contracts
}

\author{
Análisis del Reparto Óptimo del Riesgo de Construcción en la Contratación Pública
}

\author{
Antonio Sánchez Soliño (Main and Contact Author) \\ Polytechnic University of Madrid \\ asanoli@ciccp.es \\ Colegio de Ingenieros de Caminos, Canales y Puertos \\ (Carmen Benavente) C/ Almagro, 4228010 Madrid / Tel.: 913081988
}

\author{
Código: 0216 \\ Fecha de Recepción: 01.01.2014. \\ Fecha de Aceptación: 01.04.2014.
}

Abstract

This paper discusses a model based on the agency theory to analyze the optimal transfer of construction risk in public works contracts. The base assumption is that of a contract between a principal (public authority) and an agent (firm), where the payment mechanism is linear and contains an incentive mechanism to enhance the effort of the agent to reduce construction costs. A theoretical model is proposed starting from a cost function with a random component and assuming that both the public authority and the firm are risk averse. The main outcome of the paper is that the optimal transfer of construction risk will be lower when the variance of errors in cost forecast, the risk aversion of the firm and the marginal cost of public funds are larger, while the optimal transfer of construction risk will grow when the variance of errors in cost monitoring and the risk aversion of the public authority are larger.

Resumen

En este trabajo se elabora un modelo basado en la teoría de la agencia para analizar la transferencia óptima del riesgo de construcción en los contratos públicos de obras. El supuesto de partida consiste en un contrato entre un principal (Administración Pública) y un agente (contratista), con un sistema de remuneración basado en una fórmula de tipo lineal que incluye unos determinados parámetros que definen los incentivos para inducir el esfuerzo del contratista en la gestión de los costes. El modelo teórico se desarrolla a partir de una función de costes con un componente aleatorio, y suponiendo que tanto la Administración como el contratista presentan aversión al riesgo. Como resultados principales del trabajo cabe destacar que la transferencia óptima del riesgo de construcción al contratista será menor cuanto mayor sea la varianza de los errores de previsión de los costes de construcción, cuanto mayor sea la aversión al riesgo del contratista y cuanto mayor sea el coste marginal de los recursos públicos. Por el contrario, la transferencia óptima del riesgo de construcción será mayor cuanto mayor sea la varianza de los errores de medición de los costes y cuanto mayor sea la aversión al riesgo de la Administración.

Keywords: Incentives, Construction Risk, Public Procurement, Public Works, Risk Aversion.

INTRODUCTION: BACKGROUND AND STATE OF THE ART

There has been a notable increase in interest over recent years in the analysis of risk sharing in public procurement contracts for the provision of infrastructure and services. In more specific terms, the focus of the analysis is the optimisation of the transfer of risks between a specific public authority and a company constructing an infrastructure or managing a public service through a contractual relation between them.

A suitable theoretic framework to conduct this type of analysis is that of agency theory, which has undergone considerable development since its origins back in the 1970 's. In general terms, this theory attempts to explain the agency relationship whereby one party (the principal) delegates certain tasks to another party (the agent), and where this relation is regulated by a contract or by similar means (Jensen and Meckling, 1976). The agency problem arises under conditions of asymmetric information between the principal and the agent when there is a conflict of interest and where it is difficult or excessively expensive for the principal to verify what the agent is actually doing (Eisenhardt, 1989). In these cases, the research conducted into the principal-agent relationship is based on the specification of a series of assumptions regarding the possible means by which the principal may provide incentives to the agent in order to bring their respective objectives into line. On the basis of these assumptions and by a method of deduction, it is then possible to find a solution to the problem of contract optimization.

Agency theory has been applied to many different fields of activity and different countries ever since its origins (Harris and Raviv, 1978). Among the first studies applied to the relationship between a public authority and an agent, reference may be made to those of Loeb and Magat (1979) and Baron and Myerson (1982) that focused on the problem of the regulation of a natural monopoly under conditions of asymmetric information between the authorities (principal) and the company providing the asset or service (agent). Reference may similarly be made to the work of Laffont and Tirole (1993) on systematizing this area of economic analysis, and on extending its application to different fields, including public procurement.

The problems of information asymmetry traditionally considered within the framework of agency theory are those of adverse selection and moral hazard. Adverse 
selection refers to a situation where a principal (such as a public authority) is unaware of certain characteristics of the agent (firm) they have contracted and particularly when they may have incomplete information regarding the productive efficiency of the agent. The problem of moral hazard refers to the difficulty of the principal to observe and verify the performance of the agent, this on account that frequently the principal cannot observe the effort made by the agent to control production costs or to improve the quality of the assets or services provided. In the light of these voids in the information available to the principal, the objective of agency theory is, as stated above, to analyze the optimal forms of incentives that should be included in the corresponding contract.

The problem of the agency relationship becomes more complex when one or more of the variables involved (such as production costs) has a random component. In these cases the efficient sharing of risks between the principal and the agent takes on particular importance, this being an aspect that then requires the search for an efficient incentive mechanism. Generally speaking, the problem of risk allocation arises when there are different attitudes towards risk by the contracting parties (Arrow, 1971). In agency theory, it is generally assumed that the agent is riskaverse and the principal is risk-neutral or, at the very least, that the agent is more averse to risk (Eisenhardt, 1989; Dewatripont and Legros, 2005; Sadka, 2007), though this assumption may be questioned as is indeed considered further on in this paper.

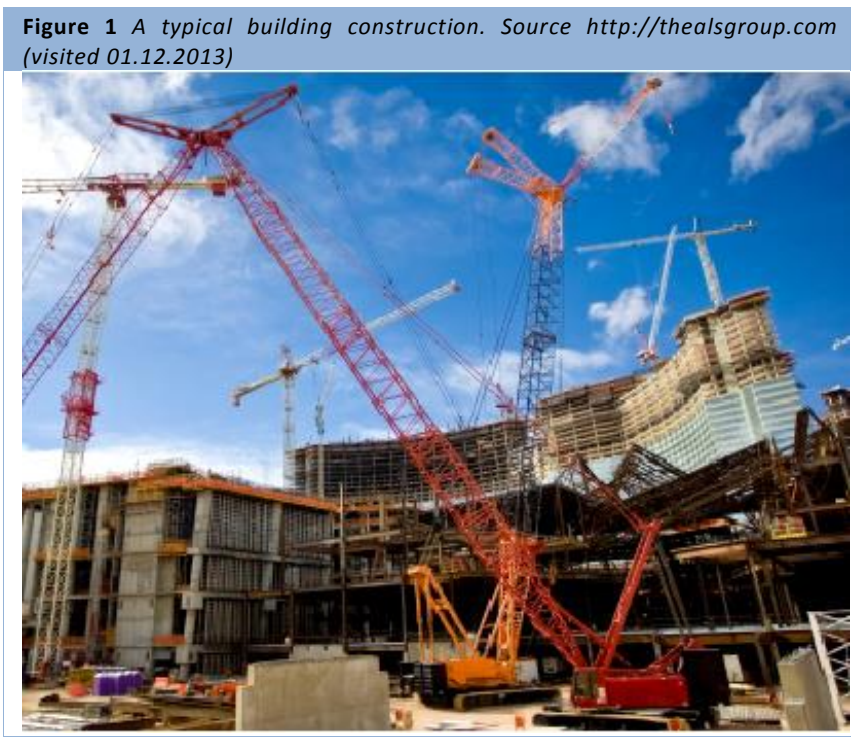

Within the area of public procurement, one particularly relevant and potentially sizeable risk is the construction risk in works contracts or other forms of contract, such as concessions or public-private partnerships. In this paper we shall consider construction risk essentially as the risk of deviation with respect to the costs budgeted for the works, for various possible reasons: incorrect specifications or measurements in the design, work delays, changes in the prices of inputs, unforeseen geotechnical problems, etc. Administrative procedures in many different countries reveal a series of different methods for allocating these types of risks. In public-private partnerships the vast majority of construction risks tend to be assigned to the contractor, while in work contracts, to the contrary, there is a greater tendency for the authorities to assume a significant proportion of these risks. For example, work contracts tend to employ price indexing formulas to protect the contractor from ensuing deviations in the costs of construction materials, energy costs or labour costs.

The criterion generally established in the literature on risk sharing is that each of the contracting parties should take on those risks they are capable of managing at the lowest cost (Debande, 2002; Huidobro et al., 2009). When following this criteria, it is accepted that the majority of the technical and economic risks (such as construction risks) should be assumed by the agent, while the principal (in this case a public authority) tends to assume the political risks (such as public opposition to the project) or those derived from situations of force majeure, such as natural catastrophes (Yescombe, 2007). However, and as we shall see in this paper, there is no theoretical basis for the complete allocation of a particular type of risk to just one of the contracting parties and, instead, an adequate risk sharing should be established in accordance with a series of parameters.

The traditional focus of public contracts under agency theory tends to concentrate on the simultaneous presence of problems of adverse selection and moral hazard. In this case, the additional presence of a random component in the cost function makes it very complicated to solve the problem (Laffont and Tirole, 1986). In the case of construction, however, and as opposed to that of other industries, cost deviations are both frequent and sizeable, partly because of the very nature of the activity. For this reason it is important to make the analysis of the principal-agent relationship under risk conditions. In this respect, the main contribution of this work is to elaborate upon the relationship between a public authority and a contractor in accordance with a function of random costs and where the problem of information asymmetry is purely restricted to a case of moral hazard, in order to make the problem more approachable. The main idea behind this focus is that, within this specific context, the application of contract incentives to the agent comes into conflict with its risk aversion and leads to a duality of objectives by, on the one hand, paying the productive work of the agent and, on the other, effectively assigning the risks, and thereby preventing the optimal outcome obtained in an environment of complete information (Holmström and Milgrom, 1991).

This work provides a model that analyses the factors giving rise to an optimal agent remuneration system, on the basis of a specific degree of transfer of the construction risk to the contractor. The proposed model focuses on a standard work contract, but its main results may be applied to the construction stage of a concession contract or any other type of publicprivate partnership. The next section outlines a basic model based on the assumption that the authorities are capable of observing and verifying the efforts made by the contractor to reduce costs. This assumption is then abandoned in the following section and, finally, we discuss the results and offer a summary of the main conclusions of the work. 
METHODOLOGY: FORMULATION OF THE BASIC MODEL

We consider a public authority (the principal in a principalagent relationship) that decides to build a specific public work by contracting a private company (agent). The contract defines the scope of the public work, specifies the qualities required and establishes a specific means of payment to the contractor. The principal will attempt to maximize a social utility function, through the optimization of the parameters defining the remuneration mechanism of the contract. This paper focuses on the said remuneration mechanisms and not on the procedure for selecting the contractor, and we shall subsequently assume that this then involves a principal-agent relationship in which both parties are already defined.

We shall assume that the agent (contractor) presents a specific cost function for the work. These costs will depend to a certain degree on the contractor's efforts to minimize the same. The variable representing these efforts shall be denominated e. We shall also assume a random cost component, as a series of unforeseen circumstances will commonly arise that can potentially affect the works, and that are (at least partially) beyond the control of the contractor. We shall then express the cost of the work as follows [Ec. 1]

$\mathrm{C}=\mathrm{C}_{0}-\mathrm{e}+\varepsilon_{\mathrm{p}}$

Where $C$ represents the cost of the work, $C_{0}$ a cost parameter of the contractor, e (a value always greater or equal to 0 ) the efforts made by the contractor and $\varepsilon_{\mathrm{p}}$ a random term representing the deviation between the real cost and the cost considered by the contractor. We shall assume that the public authority knows the $\mathrm{C}_{0}$ parameter of the contractor, and in this way may leave to one side any problem of adverse selection. The $C_{0}$ value can be interpreted as the expected cost of the work with a minimum value of effort made by the contractor with respect to cost management, this minimum value being conventionally established as $\mathrm{e}=0$.

Furthermore, the public authority may observe the cost made $C$ (though with potential errors in measurement, as we shall see further on), and we shall initially assume that they may also observe and verify the effort e made by the contractor. This latter assumption shall be abandoned in the following section.

We shall form the cost function in such a way that the variable $\varepsilon_{\mathrm{p}}$ has a normal distribution with a mean equal to 0 and standard deviation equal to $\sigma_{\mathrm{p}}$. It may be argued that the cost deviations are, in practice, almost always positive (that is to say, the real cost is greater than the expected cost), and where it would then be difficult for the mean value of $\varepsilon_{\mathrm{p}}$ to be equal to 0 . However, it is necessary to take into account that a large proportion of the cost deviations in works are the result of design modifications imposed or accepted by the public authority and these cannot always be strictly taken as random. The cost deviations referred to in equation [1] are, by way of example, those due to deviations in the expected prices of inputs (such as the price of energy), and where these may indeed be positive or negative. In all events, the contractor may always incorporate a contingency percentage on the expected value based on past experience and in this way the resulting cost deviation would be one with respect to the said "normal" percentage.

As we have already indicated, we shall assume that problems may appear when attempting to measure the cost made, and where a deviation $\varepsilon_{m}$ appears between the measured cost (or acknowledged to the contractor) and the real cost. In a similar way as with the forecast errors, we shall assume that $\varepsilon_{\mathrm{m}}$ follows a normal distribution, with a mean equal to 0 and a standard deviation equivalent to $\sigma_{m}$.

In our model the public authority shall pay the contractor according to a measured cost function (measured by the authorities, by an arbitrator or by any other means established in the contract), in accordance with a linear type equation (following Holmström and Milgrom, 1991), with a fixed component and a component representing a fraction of the cost. That is to say [Ec. 2];

$\mathrm{t}=\alpha+\omega C_{m}$

In this equation, $t$ is the amount paid by the public authority to the company, $\alpha$ is a parameter representing a fixed payment made to the company, $\omega$ is a second parameter representing a fraction of the cost reimbursed to the company and $C_{m}$ represents the measured cost. The $\alpha$ and $\omega$ parameters will be established in the contract and the object of this paper is essentially to determine the values of the said parameters that optimize a social utility function.

A value $\omega=0$ would be equivalent to a fixed-price contract, with maximum transfer of construction risk to the contractor. To the other extreme, a contract in which $\omega=1$ would imply a cost-plus or cost reimbursement contract in which all the cost deviations would be assumed by the public authority with no construction risk transfer to the contractor. Note that as $\varepsilon_{m}=C_{m}-C$, the equation [2] may be written in the following manner [EC. 3]. Where $C$ represents the cost actually made. In turn, when considering [1], we may write [Ec. 4].

$\mathrm{t}=\alpha+\omega\left(C+\varepsilon_{\mathrm{m}}\right)$
$\mathrm{t}=\alpha+\omega\left(C_{0}-\mathrm{e}+\varepsilon_{\mathrm{p}}+\varepsilon_{\mathrm{m}}\right)$

This means that the contractor's remuneration consists of a fixed amount plus a fraction of the sum of the cost expected by the contractor and the deviation due to the measurement error $\left(\varepsilon_{\mathrm{m}}\right)$ and to the forecast error $\left(\varepsilon_{\mathrm{p}}\right)$. This distinction between measurement error and forecast error was employed by Baron and Besanko (1988) in an application for public procurement contracts in the Defence sector, due to their different effects on the incentives to the contractor, as we shall see further on.

On establishing equation [4], the contractor's expected remuneration would then be as follows [Ec. 5]. While the variance in income received by the contractor, which we shall assign as $\sigma_{t}{ }^{2}$, would then be [Ec. 6]. Together with the 
social utility function, defined further on, it shall be necessary to consider the restriction established by the contractor's utility function, and where this is taken to be [Ec. 7].

$E[t]=\alpha+\omega\left(C_{0}-e\right)$

$\sigma_{\mathrm{t}}^{2}=\omega^{2}\left(\sigma_{\mathrm{m}}{ }^{2}+\sigma_{\mathrm{p}}{ }^{2}\right)$

$U f=E[z]-\psi(e)-r_{f} \sigma_{z}^{2}$

Where Uf is the utility of the contractor and the variable $z=$ $\mathrm{t}-\mathrm{C}$, that is to say, the difference between the contractor's income and the cost made. The function $\psi(e)$, with its sign, represents the disutility for the contractor of the management efforts made. This means to say that the contractor manages to reduce by an effort e the production costs of the work, but the making of these efforts implies a certain cost for the contractor that shall be incorporated within their utility function. We shall also assume that $\psi^{\prime}(\mathrm{e})$ $>0$ and that $\psi^{\prime \prime}(\mathrm{e})>0$, Which means that the $\psi(\mathrm{e})$ function is strictly increasing and convex.

In this equation, $r_{f}$ is a parameter representing the agent's attitude to risk and, when expressed in other terms, Uf would then be the certainty equivalent of the returns expected by this latter. If the agent were risk averse, this would then imply an $r_{f}$ value strictly greater than zero, while in the case of risk neutrality this would suppose an $r_{f}$ equal to zero. In our model, the agent will generally be taken to be risk averse, though we shall study the implications arising in the specific case that $r_{f}=0$. In all events we may exclude the possibility that the agent be risk seeking, and from which it will then follow that [Ec. 8]. It may then be seen that [Ec. 9-10]. And equation [7] may then be written as [Ec. 11].

$r_{f} \sigma_{z}^{2} \geq 0$

$E[z]=E[t-C]=\alpha+(\omega-1)\left(C_{0}-e\right)$

$\sigma_{z}^{2}=\omega^{2} \sigma_{m}^{2}+(\omega-1)^{2} \sigma_{p}^{2}$

$U f=\alpha+(\omega-1)\left(C_{0}-e\right)-\psi(e)-r_{f}\left[\omega^{2} \sigma_{m}{ }^{2}+(\omega-1)^{2} \sigma_{p}{ }^{2}\right]$

However, in order for the agent to carry out its activity, it will have to obtain an utility greater or equal to the alternative of not carrying out any. If we take this latter alternative to represent an utility equal to zero, the agent's participation is then dependent on the following [Ec. 12]

The social utility function, which should be maximised by the public authority, shall, in turn, be formed by the expected benefits produced by the construction of the work for society as a whole minus all costs incurred in making this building or work available, and including, among other factors, the costs derived from the risk aversion of both the agent and the authority. In this way, the social utility function may be given by [Ec. 13].
In this equation Us is the social utility that is to be maximized and the variable $S$ represents the social benefit provided by the construction of the work throughout its service life (logically expressed in terms of present value), and including both the benefits for users and the positive or negative externalities produced (with their corresponding sign). We shall take a given value for $\mathrm{S}$ that should be sufficiently large to ensure that Us $>0$, as failing this it would then be preferable not to carry out the work. As may be seen, equation [13] includes a term that represents the cost due to the risk aversion of the public authority, and where $r_{g}$ is the parameter defining this risk attitude. We shall assume that this $r_{g}$ parameter is generally positive. While in agency theory it is common to consider the principal (in this case the public authority) as risk neutral $\left(\mathrm{r}_{\mathrm{g}}\right.$ $=0$ ) (Eisenhardt, 1989), it is difficult to maintain this position today in view of the budgetary restrictions (frequently of constitutional nature) now facing most governments.

Equation [13] also includes the excess burden of public funds, given by the term $\lambda \mathrm{E}[\mathrm{t}]$, where $\lambda$ is a parameter (attributed with a value greater than zero) that characterizes the tax system of the country in question. The value $(1+\lambda)$ is normally referred to as the marginal cost of public funds, this being a concept that incorporates various aspects and including the distortion introduced by the tax system in the decisions of the economic agents and the cost of tax administration. In other words, we are then supposing that the disutility to taxpayers inflicted by levying an additional monetary unit shall be equivalent to $(1+\lambda)$ monetary units, where the value of $\lambda$ depends on the institutional framework of each country and the tax provisions used to obtain additional public funds. This weighting of public funds is not taken into account in the majority of cost-benefit analysis and it is, instead, implicitly established that $\lambda=0$. However, Laffont and Tirole (1993) considered it reasonable to establish a value $\lambda=0.3$ for the American economy and Kleven and Kreiner (2003) estimate $\lambda$ values of between 0.09 and 0.80 for different OECD countries when considering a proportional tax increase for the tax system as a whole. In all events, this concerns values that are by no means negligible. A detailed study of the concept of the marginal cost of public funds may be found in Dahlby (2008). When considering [5] and [11] and on substituting certain terms by their values, the social utility equation may then be expressed as follows in [Ec. 14]. On this definition of the social utility function, the optimisation problem may be established in the following terms [Ec. 15].

Uf $\geq 0$

$U s=S-E[C]-\psi(e)-r_{f} \sigma_{z}{ }^{2}-r_{g} \sigma_{t}{ }^{2}-\lambda E[t]$

$U s=S-(1+\lambda)\left\{C_{0}-e+\psi(e)+r_{f}\left[\omega^{2} \sigma_{m}{ }^{2}+(\omega-1)^{2} \sigma_{p}{ }^{2}\right]\right\}-$ $r_{g} \omega^{2}\left(\sigma_{p}^{2}+\sigma_{m}^{2}\right)-\lambda U f$

$\operatorname{Max}_{(U f, e, \omega)}\{U s\}$ 
When considering that the social utility function is monotonically decreasing with Uf, and that $\lambda>0$, the solution to the previous problem is then as follows [Ec. 16 to 18$]$.

$U f=0$

$\psi^{\prime}\left(e^{*}\right)=1$

$\omega^{*}=\frac{(1+\lambda) r_{f} \sigma_{p}{ }^{2}}{(1+\lambda) r_{f}\left({\sigma_{m}}^{2}+\sigma_{p}^{2}\right)+r_{g}\left(\sigma_{m}{ }^{2}+{\sigma_{p}}^{2}\right)}$

In this way we may obtain the optimal effort $\mathrm{e}^{*}$ that shall be contractually demanded of the contractor as we have assumed that this value may be observed and verified by the public authority, together with the values of the parameters optimising the remuneration mechanism of the contract from a social utility perspective. The parameter $\alpha^{*}$ may be obtained from [16], when taking into account equation [11]. As may be observed, the parameter $\omega^{*}$ shall have a value between 0 and 1 . The value of $\omega^{*}$ shall be 0 if the contractor is risk neutral $\left(r_{f}=0\right)$ and the public authority is risk averse $\left(r_{g}>0\right)$. In this case the optimal contract implies the total transfer of construction risk to the contractor. However, the risk neutrality of the public authority $\left(r_{\mathrm{g}}=0\right)$ does not imply a $\omega^{*}$ value equal to 1 : it is necessary, furthermore, that there are no cost measurement errors $\left(\sigma_{m}{ }^{2}=0\right)$. The optimal solution, purely under these conditions, would be that the public authority assumes the entire construction risk. Finally, it should be noted that under risk neutral conditions of both the contractor and the public authority, there is no specific solution for the value of the parameters defining the payment system to the contractor, as there are infinite pairs of $\alpha^{*}$ and $\omega^{*}$ values that optimise the contract.

$$
\begin{aligned}
& \frac{\partial U_{f}}{\partial e}=-\omega+1-\Psi^{\prime}(e)=0 \Rightarrow \Psi^{\prime}(e)=1-\omega \\
& \operatorname{Max}_{(\mathrm{Uf}, \mathrm{e}, \omega)}\{\mathrm{Us}\} \\
& \text { Uf }=0
\end{aligned}
$$

$-(1+\lambda)\left[-1+\psi^{\prime}\left(e^{*}\right)\right]+\psi^{\prime \prime}\left(e^{*}\right)\left\{(1+\lambda)\left[2 r_{f} \sigma_{p}^{2}\left(-\psi^{\prime}\left(e^{*}\right)\right)\right]+\right.$ $\left.(1+\lambda)\left[2 r_{f} \sigma_{m}{ }^{2}\left(1-\psi^{\prime}\left(e^{*}\right)\right)\right]+2 r_{g}\left(\sigma_{p}{ }^{2}+\sigma_{m}{ }^{2}\right)\left(1-\psi^{\prime}\left(e^{*}\right)\right)\right\}=0$

$\omega^{*}=1-\Psi^{\prime}\left(e^{*}\right)$
MODEL UNDER CONDITIONS OF

INFORMATION ASYMMETRY

The model developed in the preceding section is based on a series of hypotheses that may generally be considered as reasonable. This may even hold true, at least in certain local environments, with respect to the hypothesis regarding the awareness of the public authority of the $C_{0}$ parameter of the contractor. However, the hypothesis that the public authority may observe and verify the effort e made by the contractor is far more difficult to maintain. Strictly speaking, and under conditions of certainty, the authorities have no need to directly observe the e value if they are aware of the $C_{0}$ parameter and may observe the cost value performed C. However, if this inability to observe the $\mathrm{e}$ value is compounded by the presence of a random term in the cost function, there is then a problem of moral hazard: if there is a specific cost deviation, the public authority cannot know whether this is due to a purely random factor or due to insufficient effort by the contractor.

Under these new conditions, we may attempt to establish the optimal system of incentives that bring into line the contractor's objectives with those of the public authority, through the parameters defining the remuneration system of the contract.

$\Psi(\mathrm{e})=\mathrm{k} \mathrm{e}^{2} / 2$

$e^{*}=\frac{1-\omega^{*}}{k}$

$\omega^{*}=\frac{2(1+\lambda) k r f \sigma_{p}^{2}}{(1+\lambda)+2(1+\lambda) k r f\left(\sigma_{m}^{2}+\sigma_{p}^{2}\right)+2 k r_{g}\left(\sigma_{m}^{2}+\sigma_{p}^{2}\right)}$

The development of this model follows the same steps as the preceding section up to equations [11] and [12] that describe the utility function of the contractor and their degree of risk sharing. From this stage on, and under the new assumption that the public authority cannot observe the e value, it will now be necessary to add a further restriction, given by the maximisation of the contractor's utility, that may be obtained in the following manner [Ec. 19]. On reconsidering the problem of maximising the social utility function, we shall now take into account this new restriction. That is to say [Ec. 20], subject to restrictions [12] and [19], and where Us has the same expression as in equation [14]. The solution to this problem is then given by [Ec. 21 to 23].

In order to simplify the exposition, and advance somewhat in the interpretation of the results, it is possible to consider a specific function $\psi(\mathrm{e})$. In economic literature it is common to take the following type of quadratic cost functions [Ec. 24]. With $\Psi^{\prime}(\mathrm{e})=\mathrm{ke}$ and $\Psi^{\prime \prime}(\mathrm{e})=\mathrm{k}$, where $\mathrm{k}$ is a constant greater than 0 . Among the authors using quadratic cost functions, we may refer to Arrow and Radner (1979), Gibbons (1998), Rob and Zemsky (2002), Socorro (2007) and Martimort and Pouyet (2008). When employing this $\psi$ (e) function, the solution to the maximisation problem is then given by equation [21] plus [Ec. 25 and 26]. 
It may then be seen that the value of $\omega^{*}$ is set within the range $0 \leq \omega^{*}<1$, while the $e^{*}$ value will always be positive. Under conditions of risk neutrality of the contractor $\left(r_{f}=0\right)$, the $\omega^{*}$ value will always be equal to 0 (that is to say, with total transfer of the construction risk to the contractor), even in the case that the public authority is also risk neutral. However, a zero construction risk transfer to the contractor cannot be the optimal solution in this model, as $\omega^{*}$ cannot reach a value equal to 1 , even in the case that $r_{g}=0$ and $\sigma_{m}{ }^{2}=0$, though it may come close to 1 for high $\mathrm{k}$ values.

\section{DISCUSSION AND CONCLUSIONS}

When taking the quadratic function $\Psi(\mathrm{e})=\mathrm{k} \mathrm{e}^{2} / 2$, the result expressed by equation [17] in the complete information model will then remain as follows (Ec 27).

When comparing the result given by equation [25], it may be seen that the effort made by the contractor to control production costs under conditions of information symmetry will generally be greater than that under conditions of information asymmetry, as $\omega^{*} \geq 0$. The effort made by the contractor under conditions of information asymmetry will only be equal to that given by [27] in the case that the agent is risk neutral.

Similarly, on comparing the equation [18] in section 2 with [26] in section 3 , it may be seen that the $\omega^{*}$ parameter is lower under conditions of information asymmetry, which then infers that the optimal degree of construction risk transfer to the contractor in this latter case would be greater than that given under conditions of information symmetry.

These results are not totally intuitive and take on the following economic consequences: under conditions of information asymmetry, the public authority cannot verify (and subsequently cannot contract) the effort made by the agent. As such, in order to motivate the correct management of construction costs, the public authority would have to employ a remuneration system based on the greater transfer of construction risk to the contractor, in spite of the risk aversion of the same. However, this risk aversion restricts the use of incentives, and in this way the effort made by the contractor is lower than the optimal obtained under conditions of information symmetry. These results are summarized in figure 2 , where the suffix $c$ indicates complete information conditions and the suffix $a$ indicates asymmetric information.

When focusing on the more common case in which both the contractor and the public authority are risk averse and where there is information asymmetry, on the basis of equation [26] we may then observe the opposite effects with regards to the optimal transfer of construction risk provided by an increase in the $\sigma_{\mathrm{m}}{ }^{2}$ and $\sigma_{\mathrm{p}}{ }^{2}$ variances, respectively. A greater variance in the measurement errors, given by $\sigma_{m}{ }^{2}$, leads to a lower $\omega^{*}$ value, that is to say, a greater transfer of the construction risk to the contractor. To the contrary, a greater variance in forecast errors, given by $\sigma_{\mathrm{p}}{ }^{2}$, implies a greater $\omega^{*}$ value and an ensuing lower transfer of the construction risk to the contractor under an optimal situation. Furthermore, as $\omega^{*}$ increases with any increase in $r_{f}$, the greater risk aversion of the contractor will lead to a smaller transfer of the construction risk to this latter in an optimal situation. On the other hand, the greater risk aversion of the public authority (given by $r_{g}$ ) will lead to a lower $\omega^{*}$ value and, subsequently, the greater transfer of construction risk to the contractor in an optimal situation. Finally, it may be seen that an increase in the marginal cost of public funds (given by an increase in parameter $\lambda$ ) leads to a higher $\omega^{*}$ value and, subsequently, a lower construction risk transfer to the contractor.

As such, and by way of summary of the results of this work, we may state that the optimal construction risk transfer to the contractor decreases with rises in the variance in the forecast errors of construction costs $\left(\sigma_{p}{ }^{2}\right)$, the risk aversion of the contractor $\left(r_{f}\right)$ and the marginal cost of public funds $(\lambda)$. To the contrary, the optimal transfer of construction risk to the contractor rises with a greater variance in cost measurement errors $\left(\sigma_{m}{ }^{2}\right)$ and the greater risk aversion of the authorities $\left(r_{g}\right)$. The results given by equations [25] and [26] may be applied not just to the analysis of construction risk as a whole, but to each individual risk forming part of construction risk, and taking the corresponding variances.

By way of example, one could analyse the risk due to variations in the prices of the contractor's inputs. The results obtained in this work show that some traditional clauses contained in work contracts, such as price index formulas, do not generally lead to an optimal situation. Firstly, the potential presence of risk aversion by the public authorities would lead, under an optimal situation, to a degree of risk sharing, and not the complete assignment of risk to the authority. Secondly, the potential presence of measurement errors (in this case, a discrepancy between the values given by the application of the indexing formula and the real value of prices for the contractor) would also lead to a certain transfer of risk to the contractor, even in the case that the public authority were risk neutral.

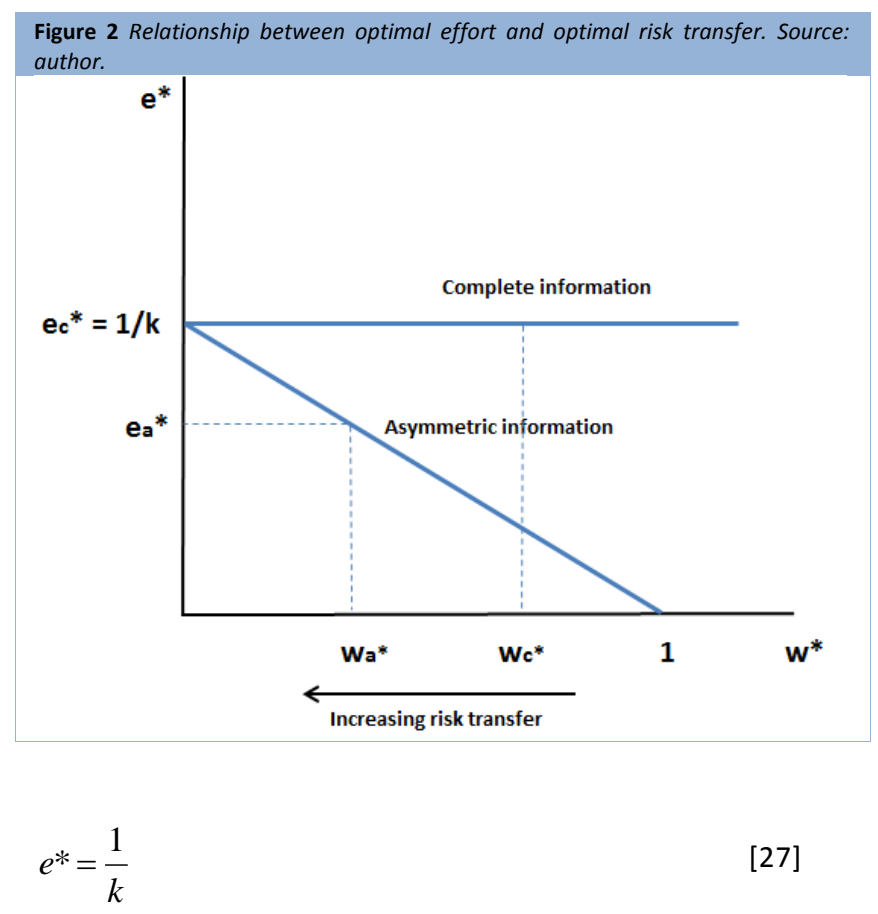




\section{REFERENCES}

Arrow, K. (1971). Essays in the theory of risk bearing. Markham. Chicago.

Arrow, K. and Radner, R. (1979). Allocation of resources in large teams. Econometrica, 47(2): 361-385.

Baron, D. and Besanko, D. (1988). Monitoring of performance in organizational contracting: The case of defense procurement. Scandinavian Journal of Economics, 90(3): 329-356.

Baron, D. and Myerson, R. (1982). Regulating a monopolist with unkown costs. Econometrica, 50(4): 911-930.

Dahlby, B. (2008). The marginal cost of public funds: theory and applications. The MIT Press, Cambridge, Massachusetts.

Debande, O. (2002). Private Financing of Transport Infrastructure. An assessment of the UK Experience. Journal of Transport Economics and Policy, 36(3): 355-387.

Dewatripont, M. and Legros, P. (2005). Public-Private Partnerships: Contract Design and Risk Transfer. European Investment Bank Papers, 10(1), 120-145.

Eisenhardt, K.M. (1989). Agency Theory: An Assessment and Review. Academy of Management Review, 14(1): 57-74.

Gibbons, R. (1998). Incentives in Organizations. Journal of Economic Perspectives, 12(4): 115-132.

Harris, M. and Raviv, A. (1978). Some results on incentive contracts with application to education and employment, health insurance, and law enforcement. American Economic Review, 68(1), 20-30.

Holmström, B. and Milgrom, P. (1991). Multitask principal-agent analyses: incentive contracts, asset ownership and job design. Journal of Law, Economics and Organization 7(Special issue): 24-52.

Huidobro, J; Heredia, B.; Salmona, M. and Alvarado, L. (2009). Inclusión de la Gestión de Riesgos en el Estudio de Ofertas para Licitaciones de Proyectos de Construcción. Revista de la Construcción, 8(2), 27-37.

Jensen, M. and Meckling, W. (1976). Theory of the firm: Managerial behavior, agency costs and ownership structure. Journal of Financial Economics, 3(4), 305-360.

Kleven, H.J. and Kreiner, C.T. (2003). The Marginal Cost of Public Funds in OECD Countries: Hours of Work versus Labor Force Participation. CESifo Working Paper no. 935.

Laffont, J.J. and Tirole, J. (1986). Using Cost Observation to Regulate Firms. Journal of Political Economy, 94(3): 614641.

Laffont, J.J. and Tirole, J. (1993). A Theory of Incentives in Procurement and Regulation. Cambridge, Mass.: MIT Press.

Loeb, M. and Magat, W.A. (1979). A decentralized method of utility regulation. Journal of Law and Economics, 22: 399-404.

Martimort, D. and Pouyet, J. (2008). Build It or Not: Normative and Positive Theories of Public-Private Partnerships. International Journal of Industrial Organization, 26(2): 393-411.
Rob, R. and Zemsky, P. (2002). Social capital, corporate culture and incentive intensity. RAND Journal of Economics, 33(2): 243-257.

Sadka, E. (2007). Public-Private Partnerships - A Public Economics Perspective. CESifo Economic Studies, 53 (3), 466-490.

Socorro, M.P. (2007). Optimal technology policy under asymmetric information in a research joint venture. Journal of Economic Behavior and Organization, 62(1): 76-97.

Yescombe, E.R. (2007). Public-Private Partnerships: principles of policy and finance. Elsevier. Oxford. 